\title{
Evolving Notions and Experiences of English Studies and Pedagogy in Contemporary India
}

\author{
Urmila $G^{*}$ and Nikhil Govind ${ }^{\dagger}$
}

\begin{abstract}
The article highlights how new sub-disciplines such as Malayalam literature are increasingly emerging as the mainstay of Literary studies in India. Though there is a debt to the British model that highlighted the canon from Chaucer to the twenty-first century, it has become increasingly clear that India will have to find its own understanding of what English Studies can best represent for contemporary Indian interests. Innovation will thus have to emerge both in terms of the content and a student-centred pedagogy. Shift in languages, with an increasing interest in gender, caste, visual culture has been an important step. In terms of pedagogy, negotiation between the need for articulations in mother tongue and English as a second language requires pedagogical reflections.
\end{abstract}

Keywords: English Studies, Pedagogy, Malayalam Language Literature

\section{Introduction}

This article consists of a chief voice-that of the intellectual and institutional autobiography of an English doctoral student, Urmila G. This voice is lightly framed by the inputs of her PhD Guide

\footnotetext{
* Manipal Academy of Higher Education (MAHE), Karnataka, India; urmisreyas@gmail.com

† Manipal Academy of Higher Education (MAHE), Karnataka, India; nikhilgovind@hotmail.com
} 
(Nikhil Govind), who has written the first two paragraphs. The idea, after this initial framing of the first two paragraphs, is to use the voice of someone who is imbricated in the very productive turmoil that English departments are undergoing today - a voice that can be used to diagnose many of our contemporary challenges and opportunities. The framing only adds a shade of emphasis that reinforces the linkages between Urmila's voice and the many themes that animate the current issue of Artha-themes such as the place and context of the English Studies today, the perceived tradeoff between English as a skill/ service department and English as high literature and necessary cultural citizenship, the formative role of the regional languages within and across 'English' literature, the centrality of practice and the lived experience of contemporary concerns such as gender justice, the issues of pedagogy and feedback, and the need to not only destroy old canons but also patiently and collaboratively build new ones of scholarship and reading practice. This article aims to use the personal voice of a doctoral scholar to highlight institutional issues of curriculum, pedagogy and pointed contemporary social relevance in the field of English Studies in India.

It is only thanks to Urmila's voice that one can measure some of the successes of English Studies in India today. This voice makes no claim to universality of experience in the text that follows but primarily seeks to draw attention to how English Studies offer the possibility of customisation to evolving ideas of student interest, ability and citizenship. Hence, the chief point of interest is not what may have been achievable in the Manipal Centre of Humanitiesthere is little here that cannot be replicated elsewhere if there is a certain assurance of dedicated faculty, and institutional supportthat is support of not just faculty to student, but of university administration to faculty. It is not within the purview of this article to investigate or validate the various pedagogical and learning experiences of different universities in the country. Rather, the thrust of this article is to affirm that while certain institutional spaces may be carved out, only the student can ultimately perform research that speaks to their individual capacities and aspirations. For example, in the following text, Urmila shows us how it is impossible to think of English studies without thinking of the preundergraduate world (i.e. of CBSE, ICSE, State Boards and so on) 
for they determine not just why one may choose to major in English but also how the initial years of an English education may really be one of unlearning an unhelpful and poorly designed CBSE exam mentality - unfortunately, the NET reproduces the poor design at an even more unfortunate career-point. There is little love for literature that one senses in such exams, and indeed literature is often the last refuge of failed commerce or science aspirants. When against such odds the student does choose English in their undergraduate years, it is rare to find teachers who are active researchers, and who are therefore able to recognise an original mind. It is many, many decades since India has produced an international scholar on Dryden, and yet, so many provincial colleges persevere in teaching these through typo-ridden guide books which are to be meaninglessly memorised. In absurd contrast, the riches of Indian literature remain unminedwhy/how would one teach bad Dryden in good Malayalam? Yet, equally importantly, it is not as if one can produce scholarship in a language just because one has spoken it all one's life. Scholarship and research belong to a specialised family of skills, and though being familiar with a regional language is a large battle won, the battle to say something original on any of the modern Indian languages is something we have just embarked on. The record (if we exclude scholarship produced abroad, and the slightly better situation in Hindi-Urdu and Bengali) is paltry, but this very paltriness can also be seen as a fertile opportunity for a more confident newer generation.

When I was twelve years old, I shifted into a State board school from an institution affiliated to the Central Board of Secondary Education (CBSE). The sudden shift in the school curriculum jarred my outlook on education. During this time, the chief concern of my parents regarding the change from a CBSE syllabus to a State board was the question of learning the English language. Anyone who had a conversation about this transfer with my parents, asked the same question: 'How will your children learn to speak fluent English?' This is because CBSE schools insisted on compulsory English speaking, while State board schools did not. Since my mother was a teacher in a State-syllabus school, she faced the dilemma of teaching her own daughters. After much discussion, my sister and I were finally transferred to her school. This was an 
institution where the majority of students came from working-class communities, and their everyday life was quite different from mine. They struggled to earn their daily allowance, to get their daily meals, to pay their monthly school bills. Many of the students joined the school to obtain a Secondary School Leaving Certificate (SSLC) so that they could immediately find a job and support their family. The pedagogy of the school prioritised an exam-oriented approach, and gaining proficiency in English language was not considered relevant. The subjects were taught in Malayalam despite their being part of an English medium school. Since CBSE students were considered to be relatively more familiar with English, and because I had studied in CBSE till my sixth grade, I felt a compulsion to demonstrate my familiarity with the language.

I chose to pursue the Humanities for my higher secondary education-a combination of subjects like English Literature, Communicative English, Economics and Gandhian Studies. Since I intended to give more attention to my proficiency in English, the two courses which I focussed on more were English Literature and Communicative English. The first year of my secondary school started with great curiosity and interest, and I eagerly read the literature of eminent writers in their unabridged form. The first classic text I read was Jane Austen's Pride and Prejudice (1813). This was an exciting beginning which encouraged me to read more of her works like Sense and Sensibility (2004/1814), Emma (2004/1815) and Mansfield Park (2004/1814). But reading unabridged versions was also a laborious task, as much of the novels consisted of long, descriptive sentences with English idioms unfamiliar to me. I persisted and made slow and steady progress, and the reading eventually led me to the oeuvres of Thomas Hardy, George Orwell, Mary Shelley, Charlotte Bronte and poets like Robert Frost, John Milton, Shelley, and Keats. Since I wanted to major in English Literature for graduation, I thought that pursuing Humanities from the secondary school level would come to my advantage. It thus came as a surprise when I found out that Humanities was a field taken by students who were unable to get into Science or Commerce streams. Most of the students were disengaged - they saw it as just a pathway to their Bachelor's degree. 
In 2010, there were only two schools in my district which offered a Humanities program at a secondary school level. This did not leave much of a choice for students who wanted to pursue a Humanities course. This situation made me reflect upon my reasons for learning Language and Literature. The method of teaching that was being followed in the school was ineffective - the literary texts were often read out loud, line by line in classes; the texts were transcribed in the vernacular language, and students were asked to memorise and recall these texts during the exams. An alternative method of teaching was hard to find and all the institutions my family and I knew, followed this model. When I joined my undergraduate programme in English Language and Literature in a college affiliated to Mahatma Gandhi University, Kottayam, the expectations regarding the course were to gain proficiency in understanding the historical, cultural, literary and theoretical aspects of the subject. The curriculum of the undergraduate degree programme included modules on both Literature and Linguistics. In the first semester of our programme, we had courses which sought to help us appreciate the position of literature within humanities. The course titled Methodology of Humanities and Literature was meant to be a guide to critically engage with language, culture, and gender. It also focussed on the idea of representation through narration. In Introduction to Language and Literature, we were provided an insight into the history of English Language and Literature, with a focus on different periods in English such as Old English Period, Middle English Period, and the Modern English Period. In the following semesters, we were introduced to courses with titles like Reading Poetry, Reading Prose, Reading Fiction, Reading Drama, Language and Linguistics, Literary Criticism, Post-Colonial Literature, Women's Literature, Indian Writing in English, Comparative Literature, American Literature and others. Under these titles, each core course promised to cover multiple texts and writers. The same syllabus was followed by every English department affiliated to the University. According to the course structure given by the University, these subjects were supposed to enhance the level of critical thinking in students, and to make students aware of the interdisciplinary nature of the subject. This seemed to be a comprehensive and ambitious curriculum for an undergraduate degree program. 
In an undergraduate program, the guidance of the teacher is crucial, especially considering the fact that most of the students come from varied educational backgrounds. Teachers become the only medium of guidance through the learning process in understanding and conceptualising their own viewpoints, in building a foundational understanding of the subject, and in developing creative and academic writing skills. The common practice of teaching was the method of transcribing the literary texts in the regional language to make learning easier for the student. This way of reading, without being aware of the social, cultural and political factors informing the text (for example, how colonialism affected the English novel), is one of the drawbacks of this method of teaching. The teaching focussed on the written exam format, where the students memorised the texts word by word. Written assignments were not a significant part of the curriculum, for even when they were written, the instructors did not give the assignments much importance. Due to this, the students showed an inclination to copy their assignments from online resources. The English department, where creative writing and critical thinking ought to take place, turned into a space that created the opposite effect. The learning experiences I had within those undergraduate English classes revealed a pedagogy that was not systemised enough to create a space for the students to have any intellectual conversations and critical thinking in the classrooms. One of the reasons for this is the obvious hierarchy that exists between a teacher and a student in an undergraduate college, where the former is an unquestioned authority and the latter is subservient to him/her. This unequal dynamic, where one party is always the speaker and the other is always a listener, did not open room for insight or new readings.

Students, quite often, do not realise how these flawed pedagogical methods limited them from finding their creative and academic capabilities. This kind of learning and teaching practice had always caused discomfort. But it was in the final semester, when the students had to do a mandatory project of 10,000 words that I saw how ill-equipped we were in writing a research paper. This project was the first crucial written exercise that students had to undertake during the three-year course. Academic writing was a topic which had never come up during the English classes. Students did not 
have any understanding of the objective of academic researchthey did not understand the meaning of literature review, the importance of citations, or even the ethical concerns regarding plagiarism. Even without any basic knowledge concerning the methodological aspects of research, the students submitted their projects - it was submitted without any feedback mechanism, and the mentors did not raise any questions regarding the originality of the work, or its place in an academic conversation. All this provoked me to rethink the question of why I wanted to pursue this subject in the first place. Even though there was no definite answer, I knew that I did not want to be an unqualified tutor who had somehow passed a NET exam through mere luck, and had thus managed a livelihood.

In some contrast, the interdisciplinary approach practised at the Manipal Centre for Humanities (MCH) introduced me to contemporary scholarship and academic writing - I had joined here for my Masters in English. This postgraduate programme emphasised an inculcation of research skills and in-depth textual analysis. The programme aimed to teach students to critically engage with given texts. While offering distinctive courses on emerging areas such as Medical Humanities, Migration Literature, Environmental Humanities (as well as traditional areas such as Gender and Film Studies), the institution also encouraged me to develop my individuated research interest. In the first year, along with literature, the students were also offered courses in Sociology and Philosophy. This was a vibrant space for earnest intellectual conversation, as many academics and eminent writers visited the institution for conferences, symposiums and workshops. Students from all streams were part of the literature club and they hosted varied cultural events such as Lawn Mushaira (dedicated to reading poetry and prose), theatre performance, literature quiz, Desha Bhasha Readings (a platform to share regional literature) and so on. The innovative ways with which the Manipal Centre for Humanities approached different disciplines changed many of my misconceptions regarding "comprehending literature". I understood that English was just another language, and learning English literature within the paradigm of a humanities education did not mean merely forming grammatically correct sentences or showcasing embellished styles of writing. Students who aspired to 
learn the discipline focussed instead on engaging critically with one's ideas, and on elaborating them with substantial textual citation and genealogy. I learned much that I could apply to literature and cultural studies from the sociology courses: for example, the course titled Kinship and Family introduced us to diverse perspectives on the idea of the family, and classroom discussions centred on the notion of desire within kinship, the different forms of kinship based on blood and marriage, aspects of queer kinship, and the kinship between surrogate mothers and adoptive parents. Since I was new to the discipline, I faced difficulties in understanding some of the concepts discussed. However, the readings for the course gave a new perspective on how to focus on an argument, and to substantiate them with the help of secondary textual analysis and scholarship. For me, writing the term paper for Kinship and Family in the first semester of my post-graduation was a truly valued experience. The guidance of the mentor and her invaluable feedback encouraged me to do multiple drafts to improve my research skills. The close attention given by the faculty helped me to better understand the structure of research.

Further, periodic assignments for each course encouraged the students to develop their own insights or ideas, to engage with these concepts critically, and to respond in an academic register. For another of my colleagues, what was crucial was the "intensity and the depth with which the core texts were addressed in the classroom". The key difference of experience from his previous University was that even though the former institution also focussed on canonical texts, in Manipal students were strongly encouraged to argue and respond to the nuances of the text through writing. This was nourished from the first semester itself - one learned to read different kinds of texts (literary, filmic, oral history, secondary scholarship) in and through each other. Later semesters continued to push the boundaries: Medical Humanities, for example, was a distinct course designed to engage with the social, political and cultural discourses surrounding body and illness. This was a course which opened up a space for students to share emotional conversations regarding one's body and self. Among the many texts read in our Medical Humanities class, the distinct voices of Paul Kalanithi (in his literary memoir 
When Breath becomes Air) (2016) and Alison Bechdel (in her graphic memoir titled Fun Home: A Family Tragicomic) (2006) have been the most influential texts for me. The pedagogy also focussed on engaging with breaking-up binaries such as the normal and the abnormal, the sane and the insane, the healthy and the diseased, as well as themes such as experience, representation, pain and articulation. This course equipped the students to develop certain characteristics that helped them approach medical narratives with sensitivity and thoughtfulness. Instead of merely focussing on a text-based analysis of the work, this course also encouraged the students to interact with 'ill' individuals and to listen to their medical narratives. This aspect, which was woven into our midterm assignment, gave me the opportunity to converse with two transgender individuals in Kerala and to share their stories with the class. This was a deeply emotional experience for me, allowing me to more fully understand the complexities of the ethics of engaging and writing personal narratives of others less privileged.

A final course and its meaning for me will be discussed: this was a course titled Political and Spiritual Rhetoric (Syllabus, Manipal Centre for Higher Education, n.d.), and it was designed to explore the political and social concerns of early and mid-twentieth century India. The readings were spread across various genres like biography, autobiography, novels, essays, letters and public discourse. The aim of the course was to read the key texts of several political and literary figures by placing them in parallel to each other and by drawing thematic connections between them. Some of the texts read and discussed in class included Jawaharlal Nehru's Discovery of India (2005/1946), Bankim Chandra Chatterjee's Anandamath (2019/1882), Rabindranath Tagore's Home and World (2005/1916), and B.R Ambedkar's Annihilation of Caste (1936/2014). A session was also dedicated to engage with the history of women writers in India, and the emergence of women writing in the public realm through personal narrative. The class moved from a discussion of the nineteenth century social reform movement in Maharashtra, and then traversed through the life of key women figures like Pandita Ramabai, Rassundari Debi, Binodini Dasi, and Kashibai Kanitkar. This class on the history of women writers in India planted in me the thought of Malayalam literature and the 
women foremothers who have contributed to the cultural heritage of Kerala. While discussing Periyar's Dravidian self-respect movement, the class also read short stories by Malayalam writer and activist Lalithambika Antharjanam. This engagement with the early twentieth century writer through selected texts encouraged me to write a term paper on the topic of early Malayalam writing by women. The lack of scholarship on the writings of these early women writers persuaded me to work on this topic for my final Master's thesis-and later, this has morphed into my present doctoral dissertation, which focuses on writers such as Antharjanam (1909-1987), Saraswati Amma (1919-1975) and Rajalekshmi (1930-1965), especially their work from the thirties to the seventies.

The writing of the Master's thesis is a crucial part of the $\mathrm{MCH}$ curriculum- students are allowed to choose a topic of their own interest, and work with a Guide. One of the marked elements regarding the English Master's program is the way it encourages students with an inclination towards regional literature to explore that area in depth. This is a rarity within most English departments in India. Writing the thesis is a structured process and the last semester of the programme is dedicated chiefly for the writing of this elaborate thesis of thirty thousand words. This project has many drafts and feedback loops from the faculty. Personally, this feedback system has encouraged me to continually refine my thesis, and indeed eventually convinced me that I could also stay within academia and contribute to the field. The lack of scholarship on these canonical women writers made it an obvious choice for a substantial doctoral dissertation. But it had taken me a long journey to get here, and no doubt there is a long journey forward - yet I can say that I am happy to have found a place from where I can confidently embark on that future journey.

\section{References}

Ambedkar, B. R. (1936/2014). Annihilation of caste: The annotated critical edition. Verso Books.

Austen, J. (1813). Pride and prejudice. Retrieved from http://www. pemberley. com/janeinfo/pridprej.html

Austen, J. (1814). Mansfield park. Thomas Egerton: UK. 
Urmila and Nikhil Evolving Notions and Experiences of English Studies

Austen, J. (2004/1811). Sense and sensibility. OUP: Oxford.

Austen, J. (2004/1815). Emma. Broadview Press.

Bechdel, A. (2006). Fun home: A family tragicomic. Boston: Houghton Muffin.

Chatterji, B. C. (2019/1882). Anandamath. Orient paperbacks.

Course Structure (MA-English/Philosophy/Sociology Syllabus at $\mathrm{MCPH}$ ). (n.d.) Manipal Centre for Higher Education. https://apply.smude.edu.in/content/dam/manipal/mu/mcph/Doc uments/MA-Course\%20Structure.pdf

Kalanithi, P. (2016). When breath becomes air (1 ${ }^{\text {st }}$ ed.). New York: Random House.

Nehru, J. (2008/1946). Discovery of India. Penguin UK.

Tagore, R. (2005/1916). Home and the world. Penguin Books India. 